\title{
Is there a risk from not using GE animals?
}

\author{
James D. Murray • Elizabeth A. Maga
}

Received: 20 October 2009/Accepted: 25 October 2009/Published online: 4 November 2009

(C) The Author(s) 2009. This article is published with open access at Springerlink.com

Since the development of the first genetically engineered (GE) plants and animals for agriculture almost 25 years ago (Hammer et al. 1985; Vaeck et al. 1987), there has been a debate amongst and between scientists, regulators, and activists opposed to the introduction and use of such plants and animals in agriculture. It seems that the debate often focuses on GE as a technique that is used in isolation, rather than one tool in the realm of selective breeding that is used in conjunction with other approaches such as nutritional management, veterinary care, and animal management to solve problems. The ongoing debate has shaped international policy, resulted in numerous reviews (e.g. Wall et al. 2009), reports (e.g. FAO/ WHO Expert Consultation 2004; Royal Society 2001; NRC 2002, 2004), and regulations by national and international bodies (FAO/WHO Food standards programme codex alimentarius commission 2008; FDA-CVM 2009), and delayed the introduction of GE animals into agriculture. The debate usually raises the same list of risks or concerns, including animal welfare, loss of genetic diversity in production

J. D. Murray $(\bowtie) \cdot$ E. A. Maga

Department of Animal Science, University of California, Davis, CA 95616, USA

e-mail: jdmurray@ucdavis.edu

\section{J. D. Murray}

Department of Population Health and Reproduction, School of Veterinary Medicine, University of California, Davis, CA 95616, USA animals, "un-naturalness", food safety including potential toxicity or allergenicity, environmental damage following release, and un-intended consequences such as activation of quiescent viruses or inappropriate gene expression resulting from activation of endogenous genes by the transgene. However, one concept missing from this debate is the cost of not using this technology to benefit agriculture and thus human lives; that is, the positive components of the risk benefit analysis. Here, the above mentioned risks will be briefly summarized, as they have been covered in depth in many reports and reviews (e.g. NRC 2002), and examples of what we have to lose if GE animals are not adopted will be presented.

\section{The potential risks of GE animals}

First, the concerns about animal welfare and loss of genetic diversity are general issues for all domesticated food animals, and as such, are not unique to the production and use of GE animals. While the expression of some genes, such as growth hormone (GH) in mammals, did result in adverse affects on the well-being of the GE mammals (Pursel et al. 1990; Nancarrow et al. 1991), such work has been discontinued. The loss of genetic diversity, for example in dairy cattle breeds or many agronomically important crops, is a function of the success of selective breeding coupled with economic considerations, and is not unique to GE, nor caused directly by being GE. 
The concept of un-naturalness is related to faith and belief systems, and as such is not subject to scientific debate. Individuals objecting to GE animals based on their belief system are also likely to object to artificial insemination, embryo transfer, and/or cloning, as well as other technologies on the continuum of animal breeding.

Food safety issues may be of legitimate concern and as such must be assessed on a case-by-case basis, as new proteins may be allergenic or toxic. In such cases, protocols have been developed to determine the potential risk of a new protein, for example as outlined in the Codex Alimentarius (FAO/WHO Food standards programme codex alimentarius commission 2008). While plants contain many toxic compounds, whose expression and therefore concentration could possibly be affected by the nearby integration of a transgene, agriculturally important mammals, poultry and fish (for the most part) do not naturally express toxins and thus this is not a concern for GE animals. However, many animals do express proteins that are allergens for some individuals and the expression of the genes encoding these proteins could potentially be altered by transgene integration or expression, as well as by mutations, although the probability is slight.

The risk of environmental damage resulting from the release of GE animals, particularly fish, is again a legitimate concern and was noted in one NRC (2002) report as perhaps the most significant risk associated with GE food animals. These risks will need to assessed on a case-by-case basis with consideration given to the species involved, the specific nature of the transgene construct used and its resulting product, and the environment in the area where release might occur.

Perhaps the most difficult risks to assess are those labeled as "un-intended consequences", as they are non-specific and usually are assumed to be adverse or potentially harmful. As the scientific method can not be used to prove a negative, we need to look to our past experience to assess the potential risk. Three observations help to put this risk category into perspective. First, throughout the course of human evolution people have eaten virtually all developmental stages of most common animals, birds and fish and therefore have consumed virtually all products from the genes in these animals, including quiescent viral sequences.
Second, horizontal gene transfer in the absence of transposable elements or viral vectors is exceedingly rare, if it occurs at all, in higher eukaryotes. We do after all eat the DNA of all food species we consume each day, together with the accompanying bacterial and viral DNA sequences, yet we do not take up and incorporate functional genes from our food.

Third, we have gained considerable experience with eating GE plants over the last 15 years. To date there has only been one report of an un-intended consequence from eating a GE plant, namely BT-corn. In this instance the consequence is positive in that BTcorn suffers less insect damage and thereby incurs fewer incidences of fungal infection. This results in the amount of fumonisin, a highly toxic fungal mycotoxin, being reduced by up to 15 -fold in BTcorn (Wu 2006). Fumonisin poisoning is associated with a number of human health concerns including increased incidences of esophageal and liver cancer, still-births, and neurological developmental defects (e.g. spinal bifida) in newborns. The link to birth defects is so striking that a very strong case can be made that scientists and health professionals should strongly advocate that pregnant women, particularly in the developing world where food safety standards are much lower, should consume only BT-corn.

Combined, these observations suggest that the risk of a significantly negative adverse effect from the use of GE animals for food is fairly unlikely, particularly with the requirements for premarket approval, which among other things assesses the likelihood that the transgene product may be toxic or allergenic (e.g. FDA-CVM 2009).

\section{The risk of not using GE animals}

All of the above risks of using GE animals have been thoroughly discussed and examined, both in the scientific literature as well as the popular press. However, the risks, or cost, to human welfare from not using GE livestock, poultry and fish have yet to be addressed. GE animals are not the answer to all production or food quality problems, but there are clear areas where a GE approach can contribute to solving a specific problem where the more traditional approaches can not. GE of an animal is not carried out in isolation from other approaches used in animal agriculture, but rather is used in conjunction with 
selective breeding, veterinary intervention, nutrition, and animal management techniques. GE, or any other approach, does not need to completely solve a problem in order to be worthwhile. It simply means that the use of GE could make a positive difference in some situations and that there is a cost to human society when a technology that can contribute to solving a problem is not used. To illustrate this point, three examples will be outlined as each has, to varying degrees, been validated. The first deals with increasing animal production in the face of an increasing demand for food, the second contributes to the mitigation of the impact of animal production on surface water eutrophication, and the third proposes to use GE animals to decrease the effects of debilitating diarrhea in the developing world.

First, the human population is steadily increasing and is predicted to rise to over 9 billion people by 2050 (UN: Population Division of the Department of Economic and Social Affairs of the United Nations Secretariat, World Population Prospects: The 2008). Wheeler and colleagues have produced a line of GE pigs that express bovine $\alpha$-lactalbumin in the mammary gland, which leads to an increase in milk production, and consequently results in the successful weaning of more baby pigs per litter on average (Wheeler et al. 2001). This is a positive effect both in terms of animal welfare, in that more of the baby pigs born survive to weaning, and in terms of increasing the efficiency of production at a time when world population and demand for protein is steadily increasing.

Second, consider the EnviroPig ${ }^{\mathrm{TM}}$, a line of pigs genetically engineered to express an E. coli phytase gene in the salivary gland in response to concerns about phosphorus utilization (Golovan et al. 2001) and the effects of swine production on surface water eutrophication, a growing environmental problem across the developed and developing world. The EnviroPig ${ }^{\mathrm{TM}}$ line of animals can obtain all its required phosphorous from consumed plant material and thus does not require rations to be supplemented with non-organic phosphate, with the result that fecal phosphorus is significantly reduced. This results in animals with a significantly decreased impact on the environment, thereby increasing the sustainability of production.

Finally, milk from our human lysozyme transgenic goats (Maga et al. 2006a) has several potential benefits, including improved udder health, increased shelf-life of the milk, and increased gastrointestinal health of young animals or humans consuming the milk. Milk from the transgenic goats contains approximately 1,000 times more lysozyme than non-modified goats' milk, which is approximately $65 \%$ of the lysozyme found in normal human milk. This milk has antimicrobial properties, both in vitro (Maga et al. 2006b) and when consumed by animal models, even after pasteurization (Brundige et al. 2008). Although we have not yet tested this milk in humans, our data indicate that all the potential benefits are likely to be achieved, including the gastrointestinal benefits for humans. According to the WHO, over 2 million children die yearly from diarrheal diseases, with $E$. coli being one of the major causative organisms, bacteria whose growth and viability is clearly inhibited in vivo with the consumption of human lysozyme-containing goats' milk by young pigs.

\section{GE animals can contribute to agriculture in the future}

Each of the above examples has been shown to be potentially effective at addressing an identified problem and in each case the problem could not have been as efficiently addressed by a traditional animal breeding approach. That is not to say that a GE approach is the only possible solution or that GE alone solves the problem, but rather that by using a $G E$ approach a significant part of the problem can be addressed. Furthermore, data now exist for each of the above examples, and for other GE animals including milk cows (Laible et al. 2007), tilapia (Caelers et al. 2005), and salmon (Devlin et al. 2009), to show that GE animals can be routinely produced that are healthy, normal individuals. In each case, the expressed transgene has been shown to function as predicted and to confer a new trait or property to the animal, e.g. the ability to digest phytate, or to improve a natural trait beyond what could have reasonably been achieved by a traditional breeding approach. Perhaps most significantly, each of these lines of transgenic animals has been shown to have normal growth and reproductive parameters for their respective species and, in this regard, are no different from any other animals used in current production systems. In summary, we have demonstrated that we 
can use GE to add to the already considerable genetic variability that exists in our domestic animals through natural mutations and to address some of the significant problems that will face animal agriculture and the growing human population in the future.

The issue before us now is not whether we can safely GE our animals for specific and worthy purposes, but rather will such animals be allowed into the food chain and be accepted by the consumer. At this point we need to ask ourselves what will be lost if we do not use GE animals? Using the examples discussed above, do we choose not to use GE pigs and maintain less sustainable food production systems that harm the environment while producing inadequate amounts of food for the growing population? Do we ignore human health problems that can be uniquely addressed by GE by waiting, possibly futilely, for a more "conventional" solution over a longer time frame? Perhaps even more importantly we need to ask ourselves what are the risks, or costs, to the environment, animal welfare, and human health if GE animals are not used. Consider the possibility of using knock-out technology to end the threat of prion diseases such as mad-cow disease or scrapie as demonstrated by Richt et al. (2007) and the potential benefit to both the animals and humans. While there is no doubt that the risks of all new technologies must be investigated and mitigated, most of the GE animal applications currently being pursued have been well-characterized. This leads us to conclude that there is no question that there is a cost associated with not applying this technology in terms of lost opportunities to contribute to solving some of the major problems facing animal agriculture and feeding a growing world.

In summary, before introducing a GE animal into the agricultural production system it certainly is necessary to consider the risks, but this has to be a true risk benefit analysis that fairly weighs the risk, if any, of the GE-introduced change against the potential benefits of that change and the cost to the consumer, the producer, the environment and to the animals themselves if that GE line is not used.

Open Access This article is distributed under the terms of the Creative Commons Attribution Noncommercial License which permits any noncommercial use, distribution, and reproduction in any medium, provided the original author(s) and source are credited.

\section{References}

Brundige DR, Maga EA, Klasing K, Murray JD (2008) Lysozyme transgenic goats' milk influences gastrointestinal morphology in young pigs. J Nutr 138:921-926

Caelers A, Maclean N, Hwang G, Eppler E, Reinecke M (2005) Expression of endogenous and exogenous growth hormone (GH) messenger (m) RNA in a GH-transgenic tilapia (oreochromis niloticus). Transgenic Res 14:95-104

Devlin RH, Sakhrani D, Tymchuk WE, Rise ML, Goh B (2009) Domestication and growth hormone transgenesis cause similar changes in gene expression in coho salmon (Oncorhynchus kisutch). Proc Natl Acad Sci USA 106: 3047-3052

FAO/WHO Expert Consultation (2004) Safety assessment of foods derived from genetically modified animals, including fish. FAO, Rome

FAO/WHO Food Standards Programme Codex Alimentarius Commission (2008) FAO, Rome

FDA-CVM (2009) Guidance for industry: regulation of genetically engineered animals containing heritable recombinant DNA constructs. http://www.fda.gov/downloads/Animal Veterinary/GuidanceComplianceEnforcement/Guidancefor Industry/UCM113903.pdf

Golovan SP, Meidinger RG, Ajakaiye A, Cottrill M, Wiederkehr MZ, Barney DJ, Plante C, Pollard JW, Fan MZ, Hayes MA, Laursen J, Hjorth JP, Hacker RR, Phillips JP, Forsberg CW (2001) Pigs expressing salivary phytase produce lowphosphorus manure. Nat Biotechnol 19:741-745

Hammer RE, Pursel VG, Rexroad CE Jr, Wall RJ, Bolt DJ, Ebert KM, Palmiter RD, Brinster RL (1985) Production of transgenic rabbits, sheep and pigs by microinjection. Nature 315:680-683

Laible G, Brophy B, Knighton D, Wells DN (2007) Compositional analysis of dairy products derived from clones and cloned transgenic cattle. Theriogenology 67:166-177

Maga EA, Cullor JS, Smith W, Anderson GB, Murray JD (2006a) Human lysozyme expressed in the mammary gland of transgenic dairy goats can inhibit the growth of bacteria that cause mastitis and the cold-spoilage of milk. Foodborne Pathog Dis 3:384-392

Maga EA, Walker RL, Anderson GB, Murray JD (2006b) Consumption of milk from transgenic goats expressing human lysozyme in the mammary gland results in the modulation of intestinal microflora. Transgenic Res 15:515-519

Nancarrow CD, Marshall JTA, Clarkson JL, Murray JD, Millard RM, Shanahan CM, Wynn PC, Ward KA (1991) Expression and physiology of performance regulating genes in transgenic sheep. J Reprod Fertil 43(Suppl):277-291

NRC (2002) Animal biotechnology: science based concerns. National Acadamies Press, Washington, DC

NRC (2004) Safety of genetically engineered foods: approaches to assessing unintended health effects. National Acadamies Press, Washington D.C., USA

Pursel VG, Bolt DJ, Miller KF, Pinkert CA, Hammer RE, Palmiter RD, Brinster RL (1990) Expression and performance in transgenic pigs. J Reprod Fertil 40:235-245

Richt JA, Kasinathan P, Hamir AN, Castilla J, Sathiyaseelan T, Vargas F, Sathiyaseelan J, Wu H, Matsushita H, Koster J, Kato S, Ishida I, Soto C, Robl JM, Kuroiw Y (2007) 
Production of cattle lacking prion protein. Nat Biotechnol 25:132-138

Royal Society (2001) The use of genetically modified animals. The Royal Society, London, UK

UN: Population Division of the Department of Economic and Social Affairs of the United Nations Secretariat (2008) World Population Prospects: The 2008 Revision, http://esa. un.org/unpp

Vaeck M, Reynaerts A, Hofte H, Jansens S, De Beuckeleer M, Dean C, Zabeau M, Van Montagu M, Leemans J (1987) Transgenic plants protected from insect attack. Nature 328:33-37
Wall RJ, Laible G, Maga EA, Seidel Jr. G, Whitelaw B (2009) Animal productivity and genetic diversity: cloned and transgenic animals. Animal Agriculture's Future through Biotechnology, Part 8. CAST Issue Paper Number 43 August 2009

Wheeler MB, Bleck GT, Donovan SM (2001) Transgenic alteration of sow milk to improve piglet growth and health. Reprod Suppl 58:313-324

Wu F (2006) Mycotoxin reduction in Bt corn: potential economic, health, and regulatory impacts. Transgenic Res 15: 277-289 